\title{
Betaine inhibits vascularization via suppression of Akt in the retinas of streptozotocin-induced hyperglycemic rats
}

\author{
YOUNG-GIUN KIM ${ }^{1}$, HYUNG-HO LIM ${ }^{1}$, SUH-HA LEE ${ }^{2}$, MAL-SOON SHIN ${ }^{2}$, \\ CHANG-JU KIM ${ }^{2}$ and HYEON JEONG YANG ${ }^{3}$
}

\begin{abstract}
${ }^{1}$ Department of Oriental Medical Rehabilitation, Gil Oriental Medical Hospital, College of Oriental Medicine, Gachon University, Incheon 405-760; ${ }^{2}$ Department of Physiology, College of Medicine, Kyung Hee University, Seoul, Gyeonggi-do 130-701; ${ }^{3}$ Department of Anesthesiology and Pain Medicine, CHA Bundang Medical Center, CHA University, Seongnam, Gyeonggi-do 463-721, Republic of Korea
\end{abstract}

Received November 15, 2013; Accepted February 3, 2015

DOI: $10.3892 / \mathrm{mmr} .2015 .3613$

\begin{abstract}
Diabetic retinopathy is a severe microvascular complication amongst patients with diabetes, and is the primary cause of visual loss through neovascularization. Betaine is one of the components of Fructus Lycii. In the present study, the effects of betaine on the expression levels of vascular endothelial growth factor (VEGF) and hypoxia-inducible factor (HIF)-1 $\alpha$ in association with the Akt pathway were investigated in the retinas of streptozotocin (STZ)-induced diabetic rats using western blot and immunohistochemical analyses. The results of the present study revealed that the expression levels of VEGF, HIF-1 $\alpha$, and Akt were increased in the retinas of the STZ-induced diabetic rats. Betaine treatment attenuated this increase in VEGF and HIF-1 $\alpha$ expression via suppression of diabetes-induced Akt activation in the retinas of the diabetic rats. The results suggested that betaine may potentially be used to delay the onset of complications associated with diabetic retinopathy via inhibition of retinal neovascularization in patients with diabetes.
\end{abstract}

\section{Introduction}

Diabetes mellitus is a severe metabolic disease, and numerous complications are associated with the characteristic hyperglycemia of this disease (1-3). Of these, diabetic retinopathy is one of the major microvascular complications amongst diabetic patients, and is the primary cause of visual loss through neovascularization (1).

Correspondence to: Professor Hyeon Jeong Yang, Department of Anesthesiology and Pain Medicine, CHA Bundang Medical Center, CHA University, 59 Yatap-ro, Bundang-gu, Seongnam, Gyeonggi-do 463-721, Republic of Korea

E-mail: ganglions@hanmail.net

Key words: betaine, streptozotocin, diabetic rats, vascular endothelial growth factor, hypoxia-inducible factor-1 $\alpha$, Akt
Vascular endothelial growth factor (VEGF) is a potent angiogenic and vascular hyperpermeability factor, and has a key role in the pathogenesis underlying diabetic retinopathy (2). VEGF is produced by multiple types of cell, including retinal pigment epithelium, ganglion cells, Müller cells, pericytes and the smooth muscle cells of the human retina and choroid, and is mainly modulated by tissue oxygen content (3). The transcriptional regulation of VEGF is mediated by hypoxia-inducible factor (HIF)-1 (4).

HIF-1 is the primary hypoxic signaling protein in cells for regulating angiogenesis, and is a transcription factor that is regarded as a 'master switch', responsible for the regulation of all oxygen-dependent retinal diseases (5). Downregulation of HIF-1 inhibits neovascularization in proliferative diabetic retinopathy (4). HIF-1 is a heterodimeric transcriptional factor composed of a labile $\alpha$ subunit $(120 \mathrm{kDa})$ and a stable $\beta$ subunit (92 kDa) (5). HIF-1 $\alpha$ activity is regulated by posttranslational modification-associated processes, whereas HIF-1 $\beta$ is constitutively expressed (6). HIF-1 induces the transcription of genes whose protein products function to enhance $\mathrm{O}_{2}$ delivery, for example erythropoietin and VEGF, which stimulate erythropoiesis and angiogenesis, respectively; or to induce metabolic adaptations to facilitate function under reduced $\mathrm{O}_{2}$ conditions, including glucose transporters and glycolytic enzymes (5). HIF- $1 \alpha$ promotes neovascularization $(7,8)$, by increasing VEGF expression (9).

Akt is a member of a class of serine or threonine protein kinases, and is a major effector in the phosphoinositide 3-kinase (PI3K) signaling pathway $(10,11)$. Akt has a significant role in multiple cellular processes, including cell survival, metabolism, growth, proliferation and mobility (10), and additionally regulates vascular homeostasis and angiogenesis (11). Growth factors, cytokines and other signaling molecules stimulate HIF-1 $\alpha$ protein synthesis via activation of the PI3K/Akt signaling pathways $(10,11)$. Phosphorylated (p)Akt denotes activated Akt, and the PI3K/Akt pathway is involved in modulating the expression of HIF1- $\alpha$ and VEGF (9).

Betaine is an alkaloid, which is occasionally classified as an amino acid, that is found in capsicum, silybum (the source of liver-protective flavonoid, silymarin) and Beta vulgaris $(12,13)$. Betaine is found amongst various 
animals, plants and microorganisms, and dietary sources rich in betaine include seafood, in particular marine invertebrates, wheat germ or wheat bran and spinach. The primary physiological role of betaine is as an osmolyte and methyl donor for transmethylation. In its capacity as an osmolyte, betaine protects cells, proteins and enzymes against environmental stressors. In addition, betaine is a crucial nutrient required for the prevention of chronic diseases (12). Betaine is a component of Fructus lycii, and is known to enhance visual acuity (13). However, the effect of betaine on the neovascularization of the retinas of patients with diabetes, which is the underlying cause of diabetic retinopathy, has remained to be elucidated.

In the present study, the effect of betaine on the expression of VEGF and HIF- $1 \alpha$ in association with Akt activation in the retinas of streptozotocin (STZ)-induced diabetic rats was investigated using western blot analysis and immunohistochemistry.

\section{Materials and methods}

Animals and treatments. Forty male Sprague-Dawley rats (Dae Han Bio Link Co., Ltd., Seoul, Korea) weighing $120 \pm 10 \mathrm{~g}$ (aged five weeks) were used in the present study. The rats were housed under controlled temperature $\left(20 \pm 2^{\circ} \mathrm{C}\right)$ and lighting conditions (07:00 to 19:00 h), with ad libitum access to food and water throughout the experimental period. The experimental procedures were performed in accordance with the animal care guidelines of the National Institutes of Health and the Korean Academy of Medical Sciences (Seoul, Korea), and the study was approved by the Kyung Hee Insitutional Animal Care and Use Committee (Seoul, Korea). The animals were randomly divided into four groups ( $n=10$ per group): The control group, the STZ-induced diabetes group, STZ-induced diabetes and $250 \mathrm{mg} / \mathrm{kg}$ betaine-treated group and the STZ-induced diabetes and $500 \mathrm{mg} / \mathrm{kg}$ betaine-treated group. The control group received the same volume of water for the same duration. Betaine was purchased from Sigma-Aldrich (St. Louis, MO, USA). Four weeks following STZ administration, betaine was orally administrated to the rats once a day for 14 consecutive days at the respective doses for each group.

Induction of diabetes. Diabetes was induced in the experimental animals with a single intraperitioneal (i.p.) injection of STZ $(60 \mathrm{mg} / \mathrm{kg}$, dissolved in $10 \mathrm{mM}$ citrate buffer; $\mathrm{pH} 4.5$; Sigma-Aldrich) administered to each animal. Blood glucose levels were determined two days after STZ injection using a blood glucose tester (Arkray, Kyoto, Japan). Only those rats with blood glucose levels of $\geq 300 \mathrm{mg} / \mathrm{dl}$ were confirmed to have diabetes and used in the diabetes groups. Subsequently, blood glucose levels were measured at 0,2,4 and 6 weeks following commencement of the experiment.

Tissue preparation. The animals were anesthetized using Zoletil $50^{\circledR}(10 \mathrm{mg} / \mathrm{kg}$, i.p.; Vibac Laboratories, Carros, France), transcardially perfused with $50 \mathrm{mM}$ phosphate-buffered saline and fixed with a freshly prepared solution of $4 \%$ paraformaldehyde (Sigma-Aldrich) in $100 \mathrm{mM}$ phosphate buffer (pH 7.4; Sigma-Aldrich). The retinas were dissected and postfixed overnight in $4 \%$ paraformaldehyde with $100 \mathrm{mM}$ phosphate buffer, and then transferred into a $30 \%$ sucrose solution
(Sigma-Aldrich) for cryoprotection. A freezing microtome (CM 1510-3; Leica Microsystems GmbH, Nussloch, Germany). was used to slice $20-\mu \mathrm{m}$ coronal sections of the retinas.

Western blot analysis of VEGF, HIF 1- $\alpha$ and pAkt expression. Western blot analyses were conducted according to a previously described method $(14,15)$. Retinal tissues were lysed in ice-cold whole cell lysate buffer, which comprised $50 \mathrm{mM}$ HEPES ( $\mathrm{pH} 7.5), 150 \mathrm{mM} \mathrm{NaCl}$, $10 \%$ glycerol, $1 \%$ Triton $\mathrm{X}-100,1.5 \mathrm{mM}$ magnesium chloride hexahydrate, $1 \mathrm{mM}$ ethyleneglycol-bis- $(\beta$-aminoethyl ether)- $N, N$ '-tetraacetic acid, $1 \mathrm{mM}$ phenylmethylsulfonyl fluoride (PMSF), $2 \mu \mathrm{g} / \mathrm{ml}$ leupeptin, $1 \mu \mathrm{g} / \mathrm{ml}$ pepstatin, $1 \mathrm{mM}$ sodium orthovanadate and $100 \mathrm{mM}$ sodium fluoride. Additionally, rat retina tissues were lysed in a lysis buffer containing $50 \mathrm{mM}$ Tris- $\mathrm{HCl}(\mathrm{pH} 7.5), 150 \mathrm{mM} \mathrm{NaCl}$, $0.5 \%$ deoxycholic acid, $1 \%$ Nonidet P40, 0.1\% SDS, $1 \mathrm{mM}$ PMSF and $100 \mathrm{mg} / \mathrm{ml}$ leupeptin. The mixture was incubated at $4^{\circ} \mathrm{C}$ for $30 \mathrm{~min}$. Cell debris was removed by microcentrifugation at $19,000 \mathrm{xg}$ for $20 \mathrm{~min}$ at $4^{\circ} \mathrm{C}$, followed by snap freezing of the supernatant. The protein concentration was measured using a Bio-Rad colorimetric protein assay kit (Bio-Rad Laboratories, Inc., Hercules, CA, USA). Protein $(30 \mu \mathrm{g})$ was separated on $12 \%$ SDS-PAGE and transferred onto a nitrocellulose membrane (Schleicher \& Schuell $\mathrm{GmbH}$, Dassel, Germany). The membranes were incubated with the following primary antibodies: Mouse monoclonal anti-actin antibody (cat. no. sc-8432), rabbit polyclonal anti-HIF-1 $\alpha$ antibody (cat. no. sc-10790) and mouse monoclonal anti-VEGF antibody (cat. no. sc-7269) (1:1,000; Santa Cruz Biotechnology Inc., Dallas, TX, USA); rabbit polyclonal anti-Akt antibody (cat. no. 9272) and rabbit monoclonal anti-pAkt antibody (cat. no. 4060) (1:1,000; Cell Signaling Technology Inc., Beverly, MA, USA) at $4^{\circ} \mathrm{C}$ overnight. The membranes were then incubated with anti-mouse $(1: 2,000$; cat. no. RPN4201; Amersham Pharmacia Biotechnology GmbH, Freiburg, Germany) and anti-rabbit (1:2,000; cat. no. sc-2054; Santa Cruz Biotechnology, Inc.) antibodies at room temperature for $1 \mathrm{~h}$. Protein bands were detected using an enhanced chemiluminescence detection system (Santa Cruz Biotechnology, Inc.).

Immunohistochemical analysis of VEGF, HIFl- $\alpha$ and pAkt expression. Immunohistochemical analyses were conducted as previously described $(16,17)$. The frozen retinal sections were incubated overnight at $4^{\circ} \mathrm{C}$ with mouse monoclonal anti-VEGF antibody (1:200; cat. no. sc-7269; Santa Cruz Biotechnology, Inc.), rabbit polyclonal anti-HIF1- $\alpha$ antibody (1:500; cat. no. sc-10790; Santa Cruz Biotechnology, Inc.) and rabbit monoclonal anti-pAkt antibody (1:200; cat. no. 4060; Cell Signaling Technology, Inc.). Subsequently, the sections were incubated for a further $1 \mathrm{~h}$ at room temperature with biotinylated anti-mouse secondary antibody (1:200; cat. no. BA2000; Vector Laboratories, Inc., Burlingame, CA, USA) and biotinylated anti-rabbit secondary antibody (1:200; cat. no. BA1000; Vector Laboratories, Inc.). The bound secondary antibody was then amplified using a Vector Elite ABC kit ${ }^{\circledR}$ (1:100; Vector Laboratories, Inc.). The antibody-biotin-avidin-peroxidase complexes were visualized using 0.03\% 3,3'diaminobenzidine (Sigma-Aldrich) 
and the sections were mounted onto gelatin-coated slides (Marienfeld-Superior, Lauda-Königshofen, Germany). The slides were air dried at room temperature overnight, and coverslips were subsequently mounted with Permount ${ }^{\circledR}$ (Thermo Fisher Scientific, Waltham, MA, USA).

Statistical analysis. Following staining, the number of immunoreactive cells per $1,000-\mu \mathrm{m}$ length of retinal section were counted for each rat. Results were analyzed using one-way analysis of variance followed by Duncan's post-hoc test, and values are presented as the mean \pm standard error of the mean. Statistical analyses were conducted using SPSS version 21.0 (IBM, Armonk, NY, USA). $\mathrm{P}<0.05$ was considered to indicate a statistically significant difference between values.

\section{Results}

Effect of betaine on blood glucose levels. At 0,2, 4 and 6 weeks of the experiment, blood glucose levels were $134.08 \pm 0.84$, $134.57 \pm 4.67,137.29 \pm 12.14$ and $137.79 \pm 9.45 \mathrm{mg} / \mathrm{dl}$, respectively, in the control group; $134.08 \pm 0.84,414.14 \pm 9.75$, $458.00 \pm 40.01$ and $457.14 \pm 19.16 \mathrm{mg} / \mathrm{dl}$, respectively, in the STZ-induced diabetes group; $134.08 \pm 0.84,419.13 \pm 12.53$, $460.75 \pm 35.84$ and $405.75 \pm 19.88 \mathrm{mg} / \mathrm{dl}$, respectively, in the STZ-induced diabetes and $250 \mathrm{mg} / \mathrm{kg}$ betaine-treated group and $134.08 \pm 0.84,419.00 \pm 13.22,453.37 \pm 35.36$ and $391.75 \pm 22.75 \mathrm{mg} / \mathrm{dl}$, respectively, in the STZ-induced diabetes and $500 \mathrm{mg} / \mathrm{kg}$ betaine-treated group. Blood glucose levels were significantly increased following STZ injection $(\mathrm{P}<0.05)$. Two weeks of betaine treatment decreased blood glucose level in the diabetic rats, however this decrease was not statistically significant $(\mathrm{P}>0.05)$.

Betaine attenuates the STZ-induced increase in VEGF expression in the retina. The expression of VEGF in the retinas of the control group was set as 1.0. The expression of VEGF was $5.64 \pm 0.12$ in the STZ-induced diabetes group, $2.11 \pm 0.37$ in the STZ-induced diabetes and $250 \mathrm{mg} / \mathrm{kg}$ betaine-treated group and $1.69 \pm 0.35$ in the STZ-induced diabetes and $500 \mathrm{mg} / \mathrm{kg}$ betaine-treated group. STZ-induced diabetic rats demonstrated enhanced VEGF expression in the retina $(\mathrm{P}<0.05)$ compared with that of the control group. By contrast, betaine treatment suppressed VEGF expression in the retinas of the diabetic rats $(\mathrm{P}<0.05)$, compared with that of the STZ-induced diabetes group. A higher dose of betaine exerted a more potent suppressive effect on VEGF expression levels (Fig. 1, upper panel).

The number of VEGF-positive cells in the retinas was $7.70 \pm 0.62 /$ section in the control group, $21.48 \pm 1.56 /$ section in the STZ-induced diabetes group, 11.09 $\pm 0.99 /$ section in the STZ-induced diabetes and $250 \mathrm{mg} / \mathrm{kg}$ betaine-treated group and $12.75 \pm 1.79 /$ section in the STZ-induced diabetes and $500 \mathrm{mg} / \mathrm{kg}$ betaine-treated group. An increased number of VEGF-positive cells were detected in the retinas of STZ-induced diabetes rats compared with those of the control group $(\mathrm{P}<0.05)$. By contrast, betaine treatment inhibited this increase in the number of VEGF-positive cells in the retinas of the diabetic rats $(\mathrm{P}<0.05)$. A lower dose of betaine exerted a more potent inhibitory effect on the number VEGF-positive cells (Fig. 1, lower panel).

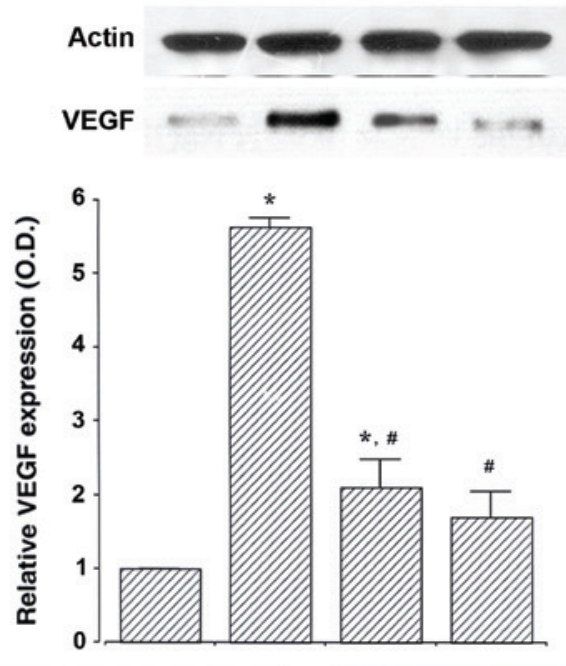

$\mathbf{A}$
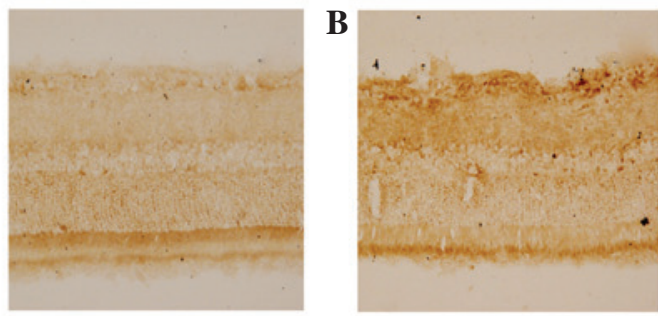

C
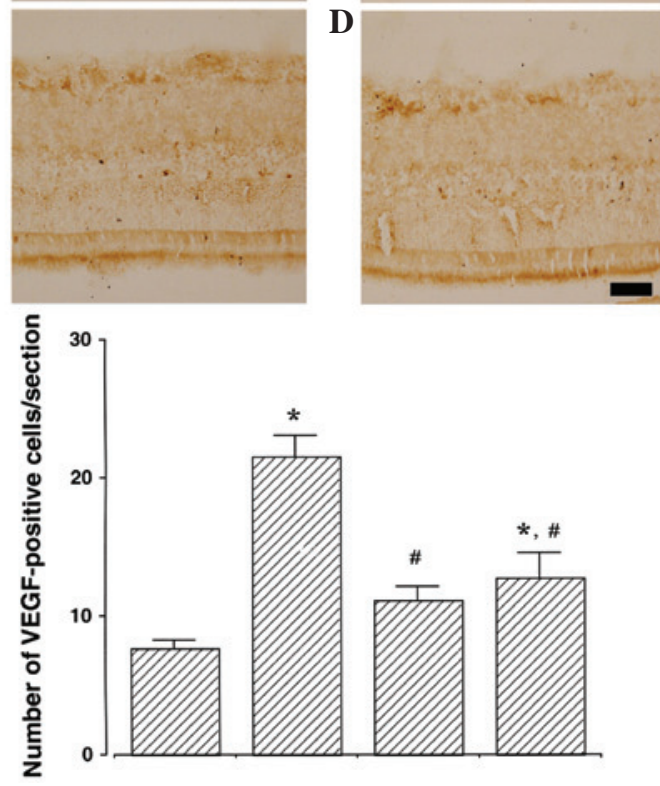

Figure 1. Effect of betaine on VEGF expression in the retina. Upper: Western blot analysis of VEGF expression. Actin was used as the internal control. Lower: Immunohistochemical analysis of VEGF expression. Scale bar, $25 \mathrm{~mm}$. Values are presented as the mean \pm standard error of the mean. (A) Control group, (B) STZ-induced diabetes group, (C) STZ-induced diabetes and $250 \mathrm{mg} / \mathrm{kg}$ betaine-treated group and (D) STZ-induced diabetes and $500 \mathrm{mg} / \mathrm{kg}$ betaine-treated group. ${ }^{*} \mathrm{P}<0.05$ compared with the control group, ${ }^{\#} \mathrm{P}<0.05$ compared with the $\mathrm{STZ}$-induced diabetes group. VEGF, vascular endothelial growth factor; STZ, streptozotocin; O.D. optical density.

Betaine attenuates the STZ-induced increase in HIF-1a expression in the retina. The expression of HIF-1 $\alpha$ in the retinas of the control group was set as 1.0. The expression of HIF-1 $\alpha$ was $5.48 \pm 0.51$ in the STZ-induced diabetes group, $1.64 \pm 0.38$ in the STZ-induced diabetes and $250 \mathrm{mg} / \mathrm{kg}$ betaine-treated group and $1.11 \pm 0.10$ in the STZ-induced diabetes and $500 \mathrm{mg} / \mathrm{kg}$ betaine-treated group. 


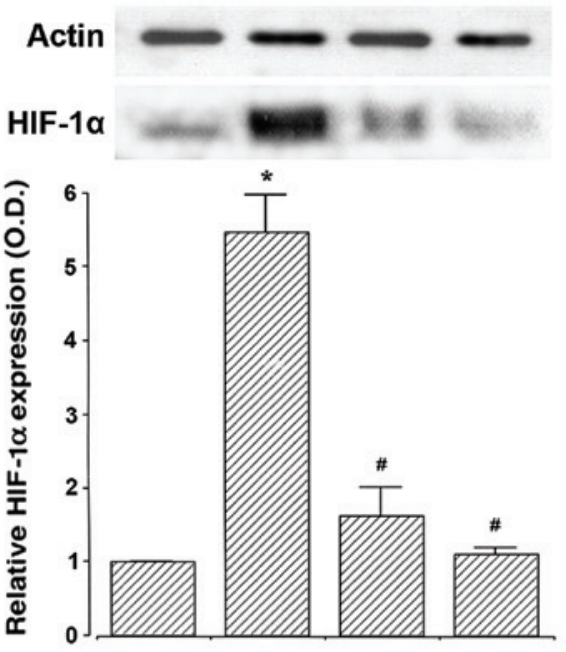

A

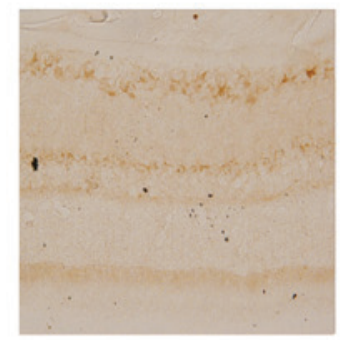

C
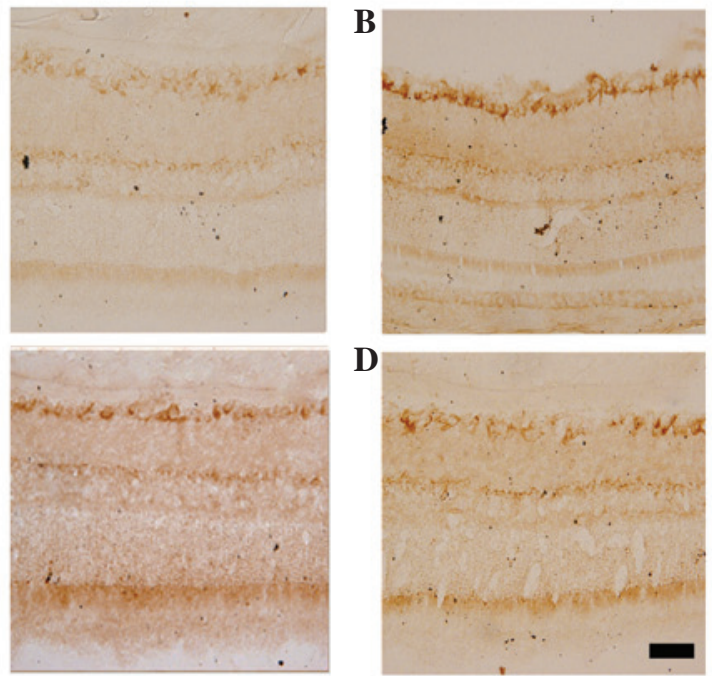

D
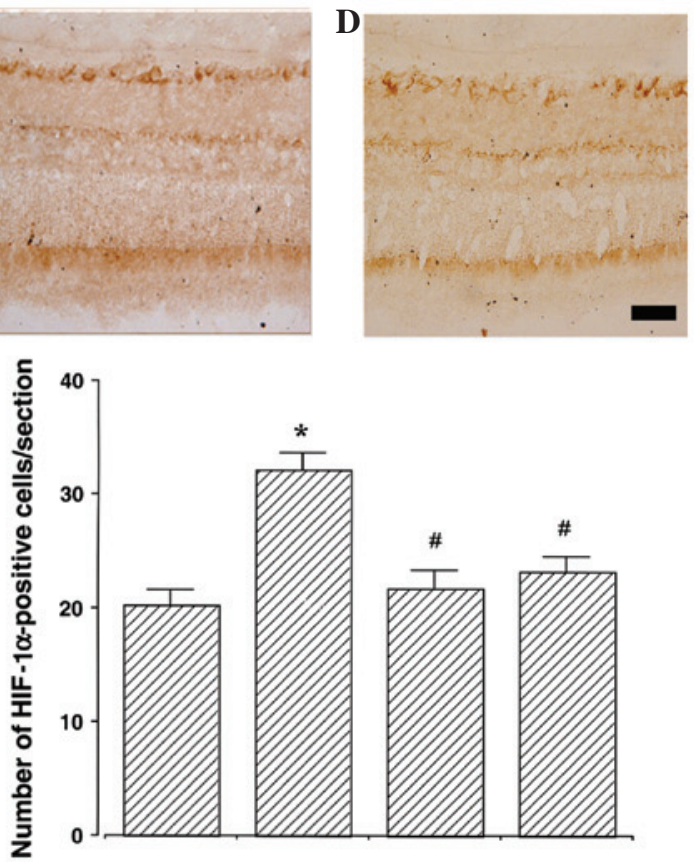

Figure 2. Effect of betaine on HIF-1 $\alpha$ expression in the retina. Upper: Western blot analysis of HIF-1 $\alpha$ expression. Actin was used as the internal control. Lower: Immunohistochemical analysis of HIF-1 $\alpha$ expression. Scale bar, $25 \mathrm{~mm}$. Values are presented as the mean \pm standard error of the mean (A) Control group, (B) STZ-induced diabetes group, (C) STZ-induced diabetes and $250 \mathrm{mg} / \mathrm{kg}$ of betaine-treated group and (D) STZ-induced diabetes and $500 \mathrm{mg} / \mathrm{kg}$ betaine-treated group. ${ }^{~} \mathrm{P}<0.05$ compared with the contro group. ${ }^{~} \mathrm{P}<0.05$ compared with the STZ-induced diabetes group. STZ, streptozotocin; HIF-1 $\alpha$, hypoxia inducible factor-1 $\alpha$.

STZ-induced diabetic rats demonstrated enhanced levels of HIF-1 $\alpha$ expression in the retina compared with those of the control group $(\mathrm{P}<0.05)$. Conversely, betaine treatment suppressed HIF-1 $\alpha$ expression in the retinas of the STZ-induced diabetes rats $(\mathrm{P}<0.05)$. Higher doses of betaine
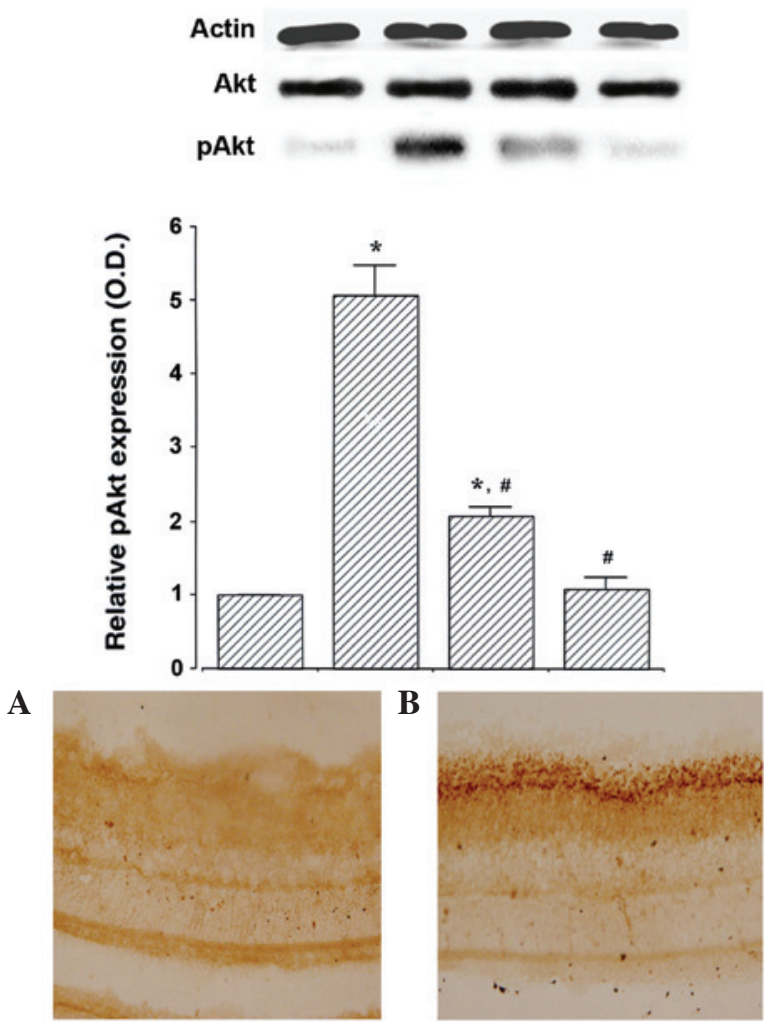

C

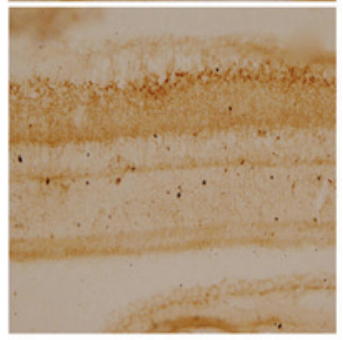

D

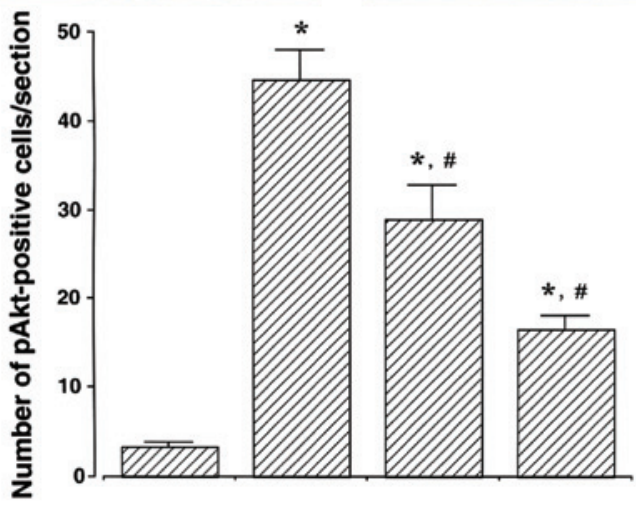

Figure 3. Effect of betaine on pAkt expression in the retina. Upper: Western blot analysis of pAkt expression. The expression of pAkt was compared with Akt expression. Lower: Immunohistochemical analysis of pAkt expression. Scale bar, $25 \mathrm{~mm}$. Values are presented as the mean \pm standard error of the mean. (A) Control group, (B) STZ-induced diabetes group, (C) STZ-induced diabetes and $250 \mathrm{mg} / \mathrm{kg}$ of betaine-treated group and (D) STZ-induced diabetes and $500 \mathrm{mg} / \mathrm{kg}$ of betaine-treated group. ${ }^{*} \mathrm{P}<0.05$ compared with the control group, ${ }^{\#} \mathrm{P}<0.05$ compared with the STZ-induced diabetes group. STZ, streptozotocin; pAkt, phosphorylated Akt.

exerted a more potent suppressive effect on the HIF-1 $\alpha$ expression, although this effect was not significant (Fig. 2, upper).

The number of HIF-1 $\alpha$-positive cells in the retinas was $20.26 \pm 1.29 /$ section in the control group, $32.16 \pm 1.49 /$ section 
in the STZ-induced diabetes group, $21.73 \pm 1.56 /$ section in the STZ-induced diabetes and $250 \mathrm{mg} / \mathrm{kg}$ betaine-treated group and $23.19 \pm 1.31 /$ section in the STZ-induced diabetes and $500 \mathrm{mg} / \mathrm{kg}$ betaine-treated group. STZ-induced diabetes rats exhibited an increased number of HIF- $1 \alpha$-positive cells in the retinas, compared with those of the control group $(\mathrm{P}<0.05)$. By contrast, betaine treatment inhibited this increase in the number of HIF-1 $\alpha$-positive cells in the retinas of the diabetic rats $(\mathrm{P}<0.05$; Fig. 2, lower panel).

Betaine ameliorates the STZ-induced increase in pAkt expression in the retina. The expression of pAkt in the retinas of the control group was set as 1.0. The expression of pAkt was $5.07 \pm 0.40$ in the STZ-induced diabetes group, $2.08 \pm 0.13$ in the STZ-induced diabetes and $250 \mathrm{mg} / \mathrm{kg}$ betaine-treated group and $1.09 \pm 0.15$ in the STZ-induced diabetes and $500 \mathrm{mg} / \mathrm{kg}$ betaine-treated group. STZ-induced diabetes rats revealed enhanced pAkt expression in the retinas compared with those of the control rats $(\mathrm{P}<0.05)$. However, betaine treatment was able to suppress this increase in pAkt expression in the retinas of the diabetic rats $(\mathrm{P}<0.05)$. A higher dose of betaine exerted a more potent suppressive effect on pAkt expression (Fig. 3, upper panel).

The number of pAkt-positive cells in the retina was $3.41 \pm 0.36 /$ section in the control group, $44.71 \pm 3.25 /$ section in the STZ-induced diabetes group, $28.87 \pm 3.82 /$ section in the STZ-induced diabetes and $250 \mathrm{mg} / \mathrm{kg}$ betaine-treated group and $16.63 \pm 1.42$ /section in STZ-induced diabetes and $500 \mathrm{mg} / \mathrm{kg}$ betaine-treated group. STZ-induced diabetes resulted in an increase in the number of pAkt-positive cells in the rat retinas compared with those in the control group $(\mathrm{P}<0.05)$. By contrast, betaine treatment inhibited this increase in the number of pAkt-positive cells in the retinas of the diabetic rats $(\mathrm{P}<0.05)$. A higher dose of betaine exerted a more potent inhibitory effect on the number of pAkt-positive cells (Fig. 3, lower panel). These results suggest that betaine is able to suppress Akt activation.

\section{Discussion}

Suppression of angiogenesis is a key therapeutic strategy in the prevention of the progression of diabetic retinopathy $(18,19)$. Steroid dexamethasone, laser photocoagulation and vitrectomy have clinically been used for the prevention of neovascularization amongst patients with diabetes $(1,18)$.

In the present study, the anti-angiogenic effect of betaine was evaluated using an STZ-induced hyperglycemic rat model. Betaine has previously been demonstrated to protect internal organs, reduce vascular risk factors and enhance athletic performance (12). Betaine reduces homocysteine level in homocystinuria, decreases serum homocysteine level and increases brain methionone and S-adenosylmethionine, functions which may delay the progression of Alzheimer's disease (20).

The STZ-induced diabetic rat model is the most widely used animal model for diabetes $(16,17)$, and is also extensively used in the study of diabetic neuropathy in particular $(21,22)$. Vascular changes, including microaneurysms, decreased pericyte number, increased vascular permeability, breakdown of blood-retinal barrier and early changes in growth factor expression, were observed in the STZ-induced diabetic rats $(23,24)$.

In the present study STZ-induced diabetic rats demonstrated enhanced VEGF expression in the retina, an effect which was attenuated following betaine treatment. VEGF is an endothelial angiogenic and vasopermeability factor, which induces functional changes in the retinal pigment epithelium (25). VEGF expression is upregulated by hypoxia and ischemia (26), and VEGF directly stimulates retinal neovascularization $(27,28)$. Enhanced expression of VEGF occurs as a result of the upregulation of survivin, which is activated by the PI3K/Akt signaling pathway (29). Suppression of VEGF expression in the retina has been demonstrated to enhance vision in multiple neovascular eye diseases, including diabetic retinopathy and age-associated macular degeneration $(30,31)$.

In the present study, STZ-induced diabetic rats additionally demonstrated enhanced HIF-1 expression in the retina. Betaine treatment suppressed this increase in HIF-1 expression in the STZ-induced diabetic rats. Previously, increased levels of HIF-1 $\alpha$ were observed in the ischemic retinas of the retinopathy mouse model, and HIF-1 $\alpha$ expression was correlated with VEGF expression (27). HIF-1 $\alpha$ regulates the expression of numerous genes required for normal cellular function and survival under various stressful conditions (32). The retina is sensitive to oxygen tension, and oxygen has a key role in the stabilization of HIF-1 $\alpha$ function. When oxygen tension is normal, HIF- $1 \alpha$ is rapidly oxidized by hydroxylase enzymes; however, when cells enter a hypoxic state, HIF-1 $\alpha$ degradation is inhibited, and HIF-1 $\alpha$ activates VEGF and erythropoietin (4-6). HIF-1 $\alpha$ is closely associated with oxygen-dependent retinal diseases, including von Hippel-Lindau, proliferative diabetic retinopathy, retinopathy of prematurity and glaucoma (4). HIF-1 mediates the role of Akt by promoting VEGF expression; therefore, promotion of the Akt-HIF-1 $\alpha$-VEGF signaling pathway contributes to the induction of angiogenesis (33).

The results of the present study revealed an increase in pAkt expression in the retinas of STZ-induced diabetic rats, an effect that was ameliorated by betaine treatment. VEGF-induced endothelial cell migration requires Akt activation (34). Activation of Akt signaling in the endothelial cells stimulates endothelial cell bioactivity and angiogenesis (35), and pAkt is predominantly expressed in the inner nuclear layer of the diabetic retina (36). Furthermore, the hypoxia-induced expression of HIF-1 $\alpha$ and VEGF requires activation of the PI3K/Akt pathway (9).

The results of the present study supported the hypothesis that Akt activation is an upper signaling pathway, which triggers a proliferative response in the endothelial cells by enhancing VEGF expression, leading to the induction of neovascularization. The results also suggested that the inhibition of Akt activation may ameliorate neovascularization via suppression of VEGF expression. In addition, betaine treatment alleviated diabetes-induced vascularization by suppressing VEGF and HIF-1 $\alpha$ expression via downregulation of pAkt expression in the retina of the STZ-induced diabetic rats. In conclusion, the results of the present study suggested a potential role for betaine in the prevention and/or delay of complications of diabetic retinopathy by inhibiting retinal neovascularization in patients with diabetes. 


\section{References}

1. Laaksonen DE,Niskanen L,Punnonen K, Nyyssönen K, Tuomainen TP, Valkonen VP, Salonen R and Salonen JT: Testosterone and sex hormone-binding globulin predict the metabolic syndrome and diabetes in middle-aged men. Diabetes Care 27: 1036-1041, 2004.

2. Qaum T, Xu Q, Joussen AM, Clemens MW, Qin W, Miyamoto K, Hassessian H, Wiegand SJ, Rudge J, Yancopoulos GD and Adamis AP: VEGF-initiated blood-retinal barrier breakdown in early diabetes. Invest Ophthalmol Vis Sci 42: 2408-2413, 2001.

3. Ishida S, Usui T, Yamashiro K, Kaji Y, Ahmed E, Carrasquillo KG Amano S, Hida T, Oguchi Y and Adamis AP: VEGF164 is proinflammatory in the diabetic retina. Invest Ophthalmol Vis Sci 44: 2155-2162, 2003

4. Arjamaa O and Nikinmaa M: Oxygen-dependent diseases in the retina: role of hypoxia-inducible factors. Exp Eye Res 83: 473-483, 2006.

5. Semenza GL: Expression of hypoxia-inducible factor 1: mechanisms and consequences. Biochem Pharmacol 59: 47-53, 2000.

6. Hewitson KS and Schofield CJ: The HIF pathway as a therapeutic target. Drug Discov Today 9: 704-711, 2004.

7. Makino Y, Kanopka A, Wilson WJ, Tanaka H and Poellinger L: Inhibitory PAS domain protein (IPAS) is a hypoxia-inducible splicing variant of the hypoxia-inducible factor-3alpha locus. J Biol Chem 277: 32405-32408, 2002

8. Matsuda T, Abe T, Wu JL, Fujiki $\mathrm{M}$ and Kobayashi $\mathrm{H}$ : Hypoxia-inducible factor-1alpha DNA induced angiogenesis in a rat cerebral ischemia model. Neurol Res 27: 503-508, 2005.

9. Yang XM, Wang YS, Zhang J, Li Y, Xu JF, Zhu J, Zhao W, Chu DK and Wiedemann P: Role of PI3K/Akt and MEK/ERK in mediating hypoxia-induced expression of HIF-1alpha and VEGF in laser-induced rat choroidal neovascularization. Invest Ophthalmol Vis Sci 50: 1873-1879, 2009.

10. Brazil DP and Hemmings BA: Ten years of protein kinase B signalling: a hard Akt to follow. Trends Biochem Sci 26 : 657-664, 2001.

11. Shiojima I and Walsh K: Role of Akt signaling in vascular homeostasis and angiogenesis. Circ Res 90: 1243-1250, 2002.

12. Craig SA: Betaine in human nutrition. Am J Clin Nutr 80: 539-549, 2004

13. Chang RC and So KF: Use of anti-aging herbal medicine, Lycium barbarum, against aging-associated diseases. What do we know so far? Cell Mol Neurobiol 28: 643-652, 2008.

14. Chang HK, Shin MS, Yang HY, Lee JW, Kim YS, Lee MH, Kim J, $\mathrm{Kim} \mathrm{KH}$ and Kim CJ: Amygdalin induces apoptosis through regulation of Bax and Bcl-2 expressions in human DU145 and LNCaP prostate cancer cells. Biol Pharm Bull 29: 1597-1602, 2006.

15. Kim DY, Jung SY, Kim CJ, Sung YH and Kim JD: Treadmill exercise ameliorates apoptotic cell death in the retinas of diabetic rats. Mol Med Rep 7: 1745-1750, 2013.

16. Jee YS, Ko IG, Sung YH, Lee JW, Kim YS, Kim SE, Kim BK, Seo JH, Shin MS, Lee HH, et al: Effects of treadmill exercise on memory and c-Fos expression in the hippocampus of the rats with intracerebroventricular injection of streptozotocin. Neurosci Lett 443: 188-192, 2008.

17. Shin MS, Kim SK, Kim YS, Kim SE, Ko IG, Kim YS, Kim CJ, Kim YM, Kim BK and Kim TS: Aqueous extract of Anemarrhena rhizome increases cell proliferation and neuropeptide $\mathrm{Y}$ expression in the hippocampal dentate gyrus on streptozotocin-induced diabetic rats. Fitoterapia 79: 323-327, 2008

18. Chen J and Smith LE: Retinopathy of prematurity. Angiogenesis 10: 133-140, 2007.

19. Kim JH, Lee BJ, Kim JH, Yu YS, Kim MY and Kim KW: Rosmarinic acid suppresses retinal neovascularization via cell cycle arrest with increase of p21(WAF1) expression. Eur J Pharmacol 615: 150-154, 2009.
20. Knopman D and Patterson M: An open-label, 24-week pilot study of the methyl donor betaine in Alzheimer disease patients. Alzheimer Dis Assoc Disord 15: 162-165, 2001.

21. Coggeshall RE, Tate S and Carlton SM: Differential expression of tetrodotoxin-resistant sodium channels Nav1.8 and Nav1.9 in normal and inflamed rats. Neurosci Lett 355: 45-48, 2004.

22. Coppey LJ, Davidson EP, Dunlap JA, Lund DD and Yorek MA: Slowing of motor nerve conduction velocity in streptozotocin-induced diabetic rats is preceded by impaired vasodilation in arterioles that overlie the sciatic nerve. Int J Exp Diabetes Res 1: 131-143, 2000.

23. Cherdshewasart W and Sutjit W: Correlation of antioxidant activity and major isoflavonoid contents of the phytoestrogen-rich Pueraria mirifica and Pueraria lobata tubers. Phytomedicine 15: 38-43, 2008.

24. Xiong FL, Sun XH, Gan L, Yang XL and Xu HB: Puerarin protects rat pancreatic islets from damage by hydrogen peroxide. Eur J Pharmacol 529: 1-7, 2006.

25. Hartnett ME, Lappas A, Darland D, McColm JR, Lovejoy S and D'Amore PA: Retinal pigment epithelium and endothelial cell interaction causes retinal pigment epithelial barrier dysfunction via a soluble VEGF-dependent mechanism. Exp Eye Res 77: 593-599, 2003.

26. Ferrara N, Gerber HP and LeCouter J: The biology of VEGF and its receptors. Nat Med 9: 669-676, 2003

27. Ozaki H, Seo MS, Ozaki K, Yamada H, Yamada E, Okamoto N, Hofmann F, Wood JM and Campochiaro PA: Blockade of vascular endothelial cell growth factor receptor signaling is sufficient to completely prevent retinal neovascularization. Am J Pathol 156: 697-707, 2000.

28. Wenger RH: Cellular adaptation to hypoxia: $\mathrm{O}_{2}$-sensing protein hydroxylases, hypoxia-inducible transcription factors, and $\mathrm{O}_{2}$-regulated gene expression. FASEB J 16: 1151-1162, 2002.

29. Huang Y, Hua K, Zhou X, Jin H, Chen X, Lu X, Yu Y, Zha X and Feng Y: Activation of the PI3K/AKT pathway mediates FSH-stimulated VEGF expression in ovarian serous cystadenocarcinoma. Cell Res 18: 780-791, 2008

30. Dugel PU: Ranibizumab treatment of patients with ocular diseases. Int Ophthalmol Clin 46: 131-140, 2006

31. Nguyen QD, Tatlipinar S, Shah SM, Haller JA, Quinlan E, Sung J, Zimmer-Galler I, Do DV and Campochiaro PA: Vascular endothelial growth factor is a critical stimulus for diabetic macular edema. Am J Ophthalmol 142: 961-969, 2006.

32. Vengellur A, Woods BG, Ryan HE, Johnson RS and LaPres JJ: Gene expression profiling of the hypoxia signaling pathway in hypoxia-inducible factor 1 alpha null mouse embryonic fibroblasts. Gene Expr 11: 181-197,2003.

33. Lee BL, Kim WH, Jung J, Cho SJ, Park JW, Kim J, Chung HY, Chang MS and Nam SY: A hypoxia-independent up-regulation of hypoxia-inducible factor-1 by AKT contributes to angiogenesis in human gastric cancer. Carcinogenesis 29: 44-51, 2008.

34. Dimmeler S, Dernbach E and Zeiher AM: Phosphorylation of the endothelial nitric oxide synthase at ser-1177 is required for VEGF-induced endothelial cell migration. FEBS Lett 477: 258-262, 2000

35. Kureishi Y, Luo Z, Shiojima I, Bialik A, Fulton D, Lefer DJ, Sessa WC and Walsh K: The HMG-CoA reductase inhibitor simvastatin activates the protein kinase Akt and promotes angiogenesis in normocholesterolemic animals. Nat Med 6: 1004-1010, 2000

36. Wang Q, Pfister F, Dorn-Beineke A, vom Hagen F, Lin J, Feng Y and Hammes HP: Low-dose erythropoietin inhibits oxidative stress and early vascular changes in the experimental diabetic retina. Diabetologia 53: 1227-1238, 2010. 